\title{
The behaviour of roof gable walls under the effect of earthquake load
}

\author{
M. Kamanli ${ }^{1}$ and F. S. Balik ${ }^{2}$ \\ ${ }^{1}$ Selçuk University, Eng. \& Arch. Faculty, Dept. of Civil Engineering, Konya, Turkey \\ ${ }^{2}$ Selçuk University, Ereğli School of Higher Education Civil Programe, Ereğli, Konya, Turkey
}

Received: 8 December 2009 - Revised: 26 January 2010 - Accepted: 27 January 2010 - Published: 11 February 2010

\begin{abstract}
In this study, the effect of earthquake loads on roof gable walls and the behaviours of these roof gable walls are investigated. In preparation of the study, two experiments on cradle roof system which gets and does not get any loads off the roof members were carried out in all. The experiments were performed on the shaking table in Earthquake Research Department of General Directorate of Disaster Affairs. Through the experiments, some considerable results were obtained on the behaviours of roof gable walls under the effect of horizontal dynamic loads. The results obtained at the end of these examinations are given and discussed. Furthermore, suggestions to make the brick gable walls more reliable against the loads of earthquake are given. When the results of the experiments were generally taken into consideration, it was realized that the gable walls in both roof systems would partly or completely collapse even under the effect of a little horizontal dynamic load.
\end{abstract}

\section{Introduction}

The researches that have been performed for long years put forth into consideration that our country is a risky one in terms of earthquakes. The earthquakes occurred until now also show that how serious it is. These experienced earthquakes have damaged constructions significantly and caused death of thousands of people (Mengi et al., 1991). It is possible to investigate these damages in constructions under the effect of earthquakes in two groups (Klemenc, 1997).

The first and most important group of these damages include the ones which occur in the conveying systems of the construction. The second damage group, on the other hand, includes the damages which occur in the parts of construc-

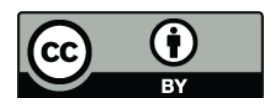

Correspondence to: M. Kamanli (kamanli@selcuk.edu.tr) tions constructed with the aim of architecture (Hahn, 1997). The damages that occur in the architectural parts of the constructions due to the effect of earthquakes may sometimes be as important as the ones in the first group (Kaltakci et al., 2007). In other words, these different types of damages occur in the architectural parts of constructions may damage to the lives and goods of human beings (Balik, 2004).

Starting out from these realities, the behaviour of roof gable walls, which are one of the architectural parts of constructions constructed in our country, under the effect of earthquake load was investigated empirically. The experiments were carried out by constructing roof systems in Figs. 1 and 2 on $6.00 \times 5.00 \mathrm{~m}$ shaking table in Earthquake Research Department of General Directorate of Disaster Affairs (TEC, 2007). According to the results of the experiments, it was also searched which precautions should be taken to make roof gable walls more secure against earthquake load and suggestions were given about this. Thus, in our country, the construction of roof gable walls being more secure against the effect of earthquake and preventing the deaths and financial damages as a result of any earthquakes will be provided.

\section{Materials}

\subsection{The materials used in the construction of experimental roofs}

The following materials were used in the construction of gable walls of experimental roofs:

1. $19 \times 29 \times 13.5 \mathrm{~cm}$ sized conveying vertically perforated bricks ${ }^{1}$ produced according to TS 705 together with $19 \times 19 \times 13.5 \mathrm{~cm}$ sized horizontal coring bricks ${ }^{2}$ produced according to TS 4563 ,

\footnotetext{
${ }^{1}$ TBC-EN-771-1: solid brick and vertically perforated bricks

${ }^{2}$ TBC-EN-771-1: horizontal coring bricks
}

Published by Copernicus Publications on behalf of the European Geosciences Union. 


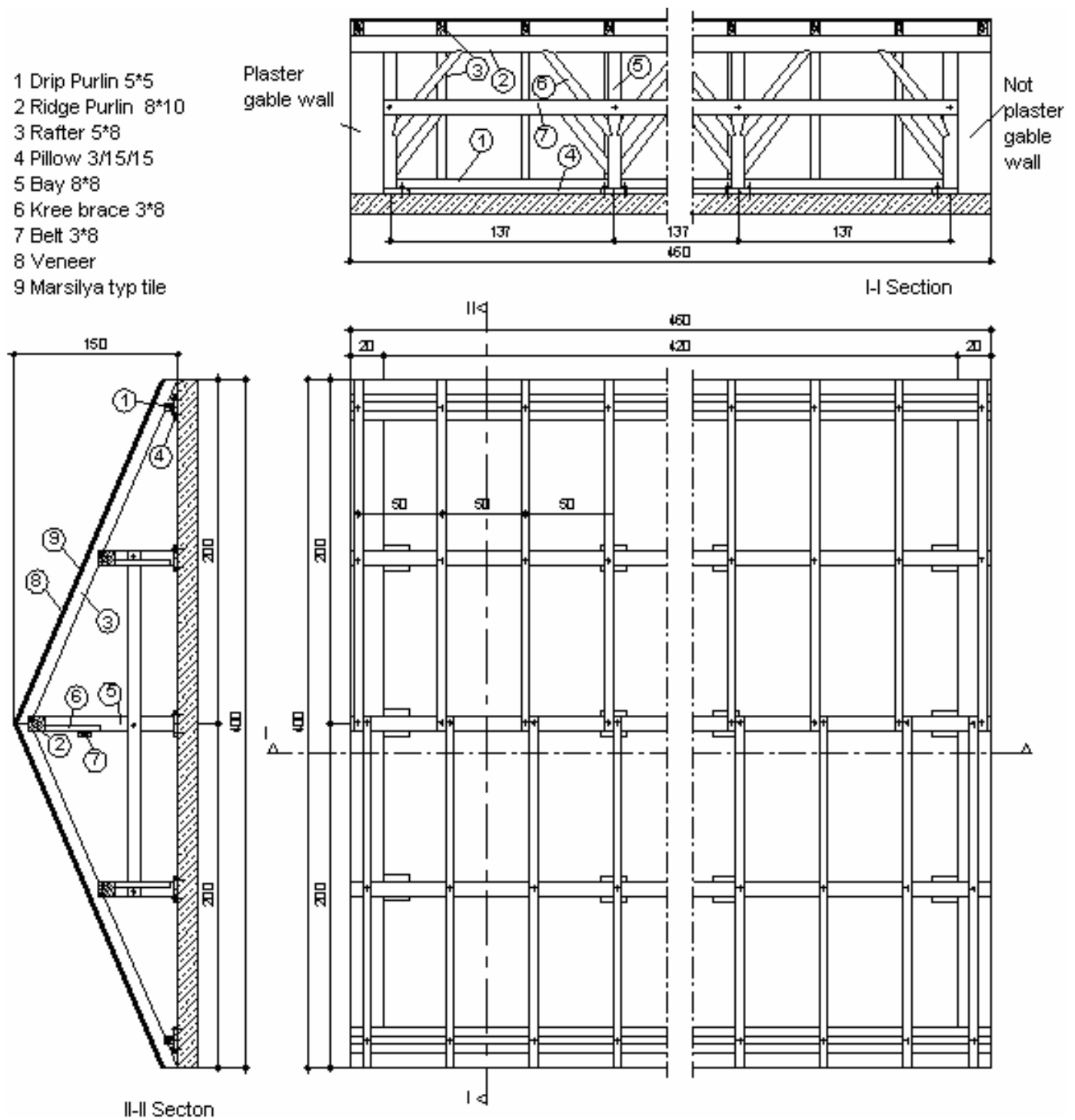

Fig. 1. The cradle roof system with gable wall that gets loads off the roof members.

2. $0 / 4 \mathrm{~mm}$ medium sand according to TS 2717 in the production of plaster mortar ${ }^{3}$ and pointing stuff (Balik et al., 2003),

3. Portland Mixed Cement ${ }^{4}$ (PKÇ/B 32.5) which has 28 day compressive strength of $325 \mathrm{~kg} / \mathrm{cm}^{2}$ and produced according to TS 12143 is used in the production of mortar,

4. hydrated lime in the production of mortar.

The wood elements of the roof were made of second class pine timber, the sizes of which were given in Figs. 1 and 2.

\footnotetext{
${ }^{3}$ TBC-2717: aggregates for mortar

${ }^{4}$ TBC-EN-197-1: cement-portland composite
}

Moreover, Marsilay typ tile and ridges which are commonly produced in our country according to TS 562 were used as a roof covering.

\subsection{The properties of shaking table}

The table is fixed on the supports made of elastic neopren wedges which provide the shaking effect (Schweiver et al., 2004). These supports have a high rigidity against vertical loads and load conveying capacity as well as they are quite flexible in the horizontal direction (Paulson et al., 1991). The wedges can make $5 \mathrm{~cm}$ horizontal translatory motion. These wedges can also be used as maximum 4 lines by connecting them over and over (Bayülke, 1986). The shaking table in Earthquake Research Department is placed on totally 
1 Drip Purlin $5 * 5$

2 Ridge Purlin $8 * 10$

3 Rafter $5 * 8$

4 Pillow $3 M 5 M 5$

5 Bay $8 * 8$

6 Kree brace $3^{\star} 8$

7 Belt $3^{\star} 8$

8 Veneer

9 Marsilya typ tile

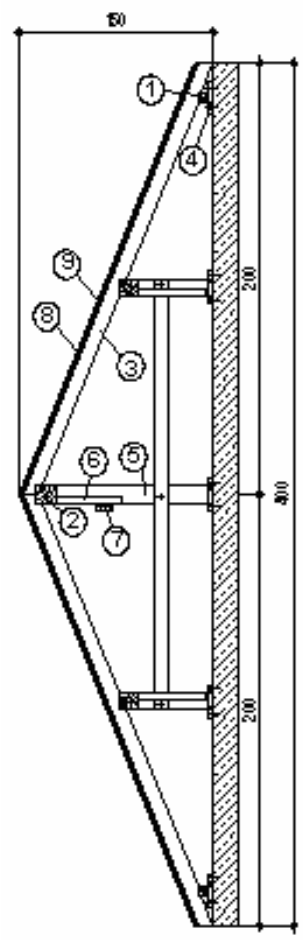

\|-II Secton

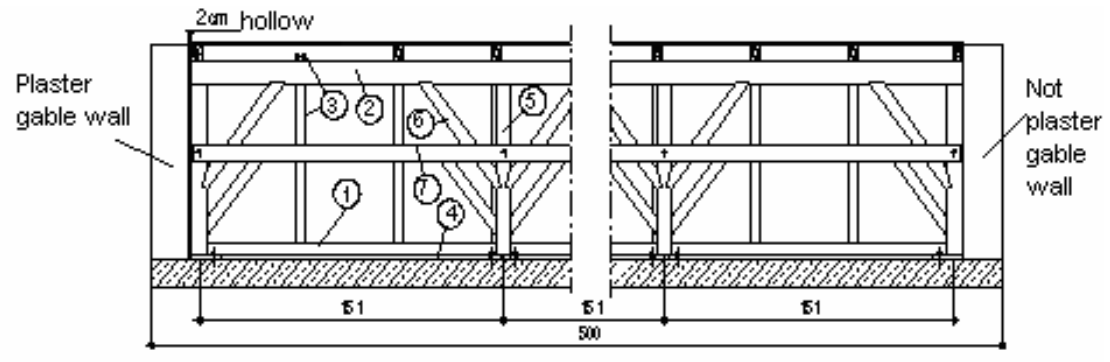

I-I Section
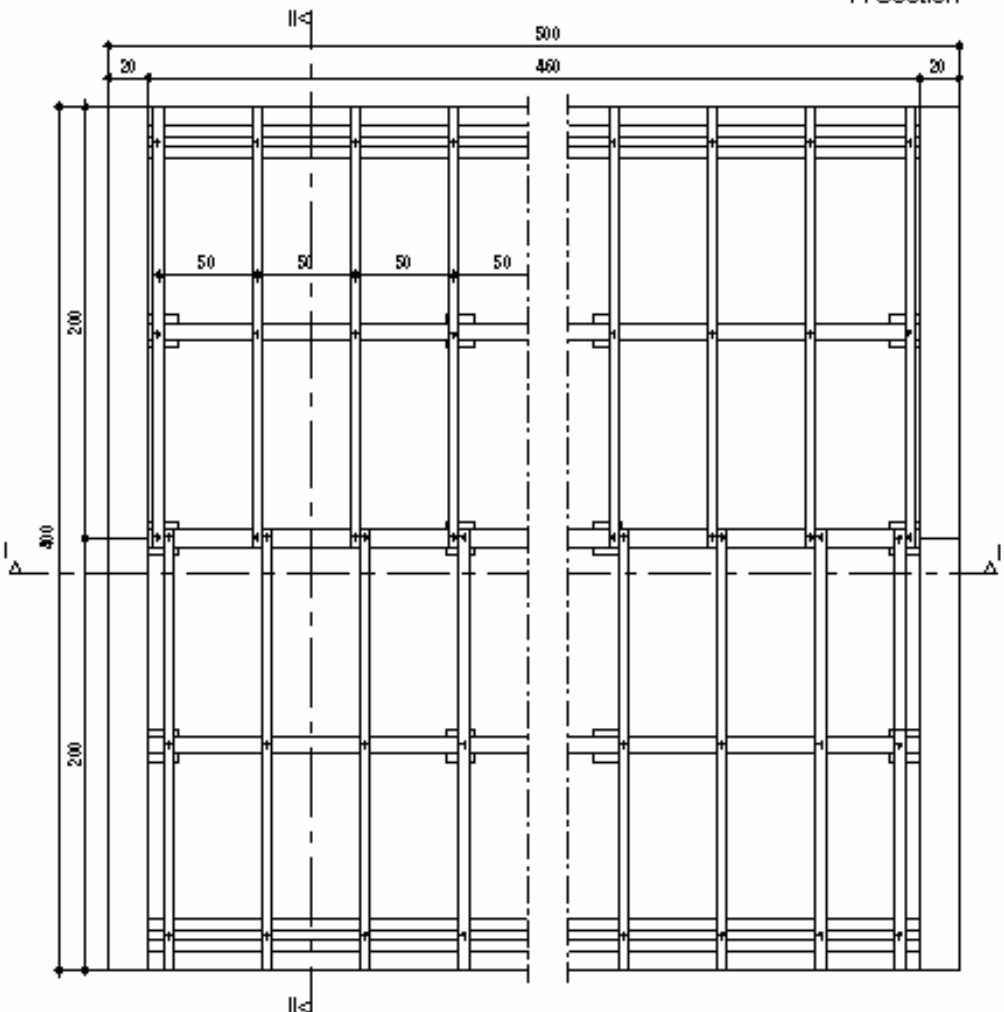

Fig. 2. The cradle roof system with gable wall that does not get vertical loads off the roof members.

248 neopren wedges as in two lines being 124 elastic neopren wedges on each line. Various appearances of neopren wedges and the table are given in Fig. 3 (Bayülke, 1990).

The setup in Fig. 4 is benefited for giving the beginning translatory motion to the table. When the beginning translatory motion is given to the shaking table, deformations in vertical direction of neopren wedges are also formed. As the table decompresses, an oscillation in vertical direction also occurs (Bayülke et al., 1986). A The oscillation under the effect of a certain beginning translatory motion may continue for $1.5 \mathrm{~s}$ (Cenvone, 2005). It is accepted that making 8-10 times oscillations by one after another with the same or different beginning translatory motion is equal to the application of an earthquake ground motion to the the model structure for 12-15 s (Bayülke et al., 1989).

\subsection{The properties of accelaration recorders}

In the experiment, the accelaration values of the table were measured by using Akashi Jep-6A3 three-axial receiver which was fixed to the shaking table with anchorage. These measured accelaration values were written numerically by Hakusan Datamark LS-800WD recorders. These records were then transferred to the computers and printed out as graphics.

\section{Method}

This study was performed in two stages:

At the first stage of the study, the gabled cradle roof system which does'nt get vertical load from the roof members was fixed on the shaking table (Fig. 1). $19 \times 29 \times 13.5 \mathrm{~cm}$ vertically perforated bricks were used in gable walls. The inner 


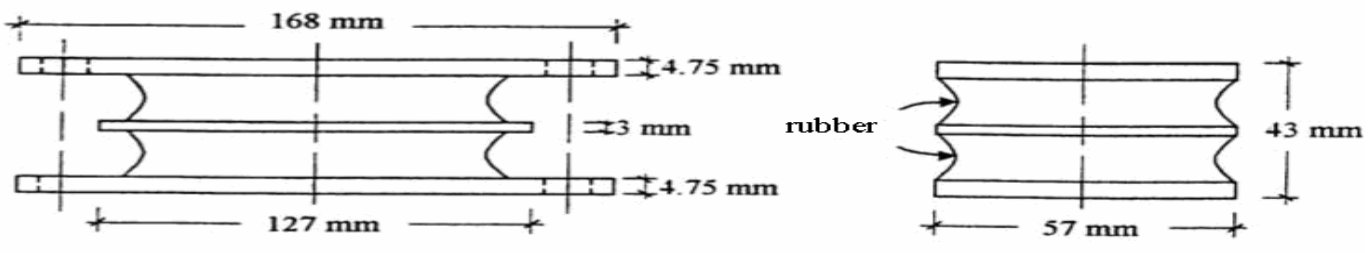

(a)
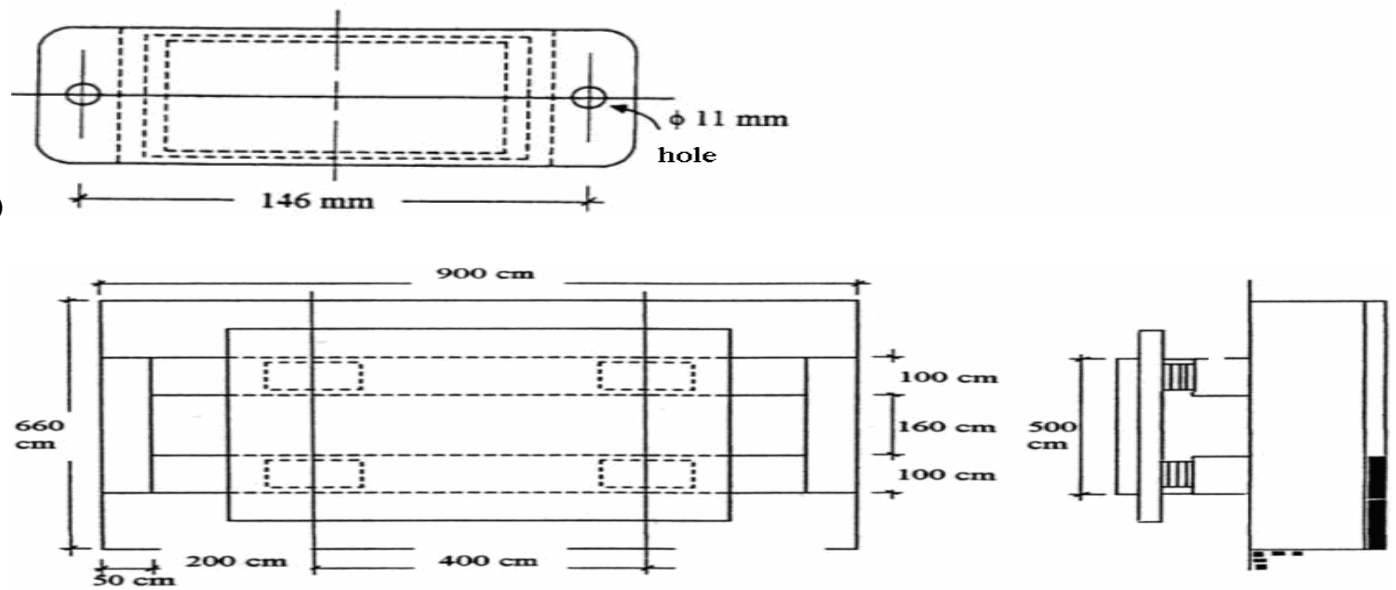

(b)

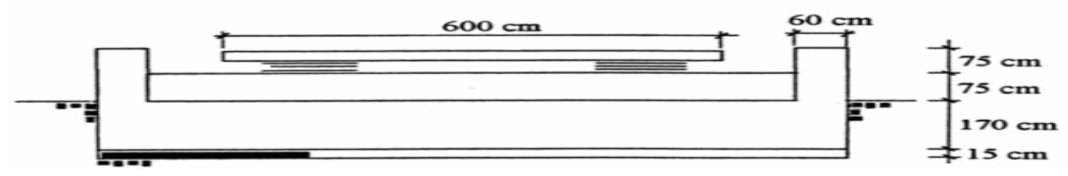

Fig. 3. The details of brace chock and shaking table. (a) Brace chock. (b) Various views of shaking table.

and outer surfaces of gable wall at one side of the roof were plastered with $2 \mathrm{~cm}$ thick plaster and $0.8 \mathrm{~cm}$ thin plaster, respectively. The surfaces of other gable wall, on the other hand, were without plaster. After 28 days, artificial earthquake effect formed by shaking table was applied and the behaviours, crack situations and displacement situations under the effect of this loading were investigated.

At the second stage of this study, the gabled cradle roof system which gets load from the roof members was fixed on the shaking table (Fig. 2). $19 \times 29 \times 13.5 \mathrm{~cm}$ horizontal coring bricks were used in gable walls. The outer surface of gable wall at one side of the roof was plastered with $2 \mathrm{~cm}$ thick plaster and $0.8 \mathrm{~cm}$ thin plaster, respectively. The surfaces of other gable wall was left without plaster. Moreover, similar errors as application errors in constructions were made in the construction of roof gable walls. For example; the cement stored in humid medium was used in the production of mortar for the bonding and plastering of gable walls and approximately a $2 \mathrm{~cm}$ gap was left between plastered gable wall and the roof. After 28 days, the behaviours, crack situations and displacement situations of this roof system under the effect of artificial earthquake were investigated.
In the experiments, the accelarations of the table were measured and recorded by three-axial receiver (accelaration recorders) fixed on the table and these recorded information was printed out as graphics. Moreover, the situations of roof members (bay, purlin, rafter, etc.) after the effect of shaking were investigated as well as investigation of gable walls.

\section{Experiments and results}

\subsection{First experiment and its results}

The first experiment was performed on the gabled cradle roof system which gets load from the roof members. 10 beginning translatory motions were applied to the shaking table in the experiment and then it was decompressed. The shaking table oscillated for $1.5 \mathrm{~s}$ at each translatory motion. The total period for these oscillations was approximately $10-15 \mathrm{~s}$. Three measurable table accelaration values during shaking are given in Table 1 and as a graphic in Fig. 5. The weight of the roof was calculated as approximately 4.5 tons. The weight of the roof was multiplied with maximum accelaration values measured for the roof and the horizontal loads that affect the roof were approximately determined. However, the horizontal loads that affected the roof were not calculated in the experiment since accelaration meter was not installed on the roof. 
(a)

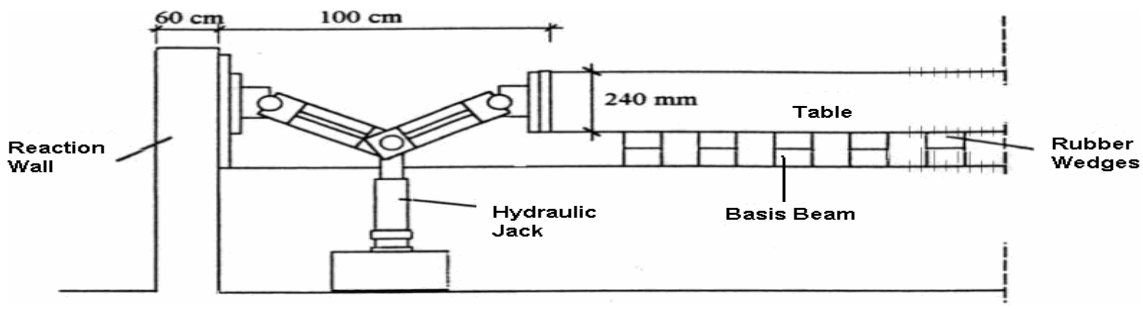

(b)

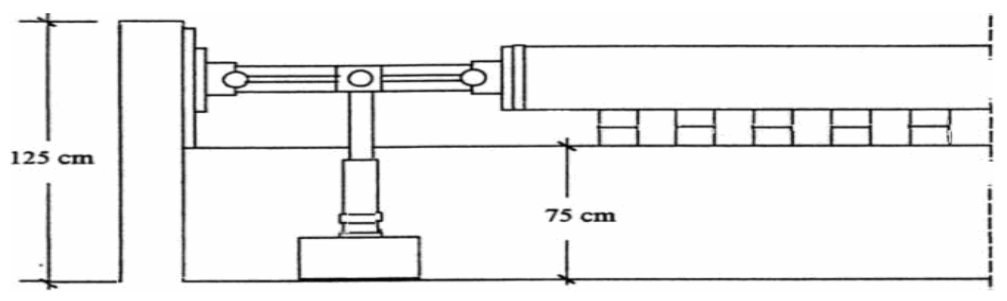

(c)

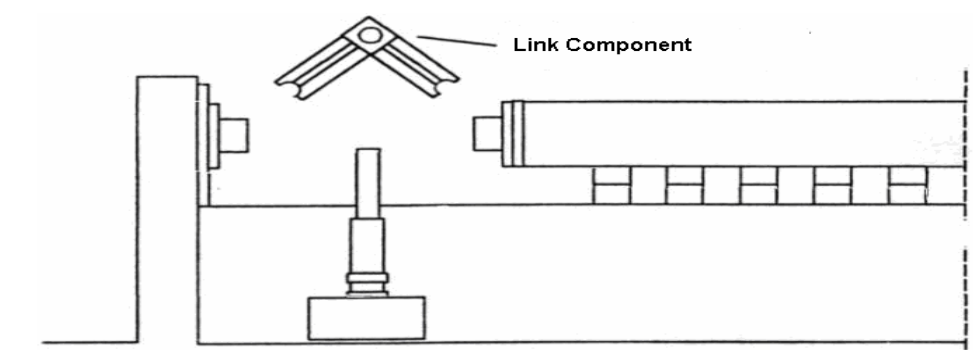

Fig. 4. The mechanism of shaking table. (a) Position before the test. (b) Position just before the initioution of vibration. (c) Position when vibration is started.

After 1st loading with $15 \mathrm{~mm}$ beginning translatory motion, microcracks were formed throughout the gable wall at the level of first line bricks on the bottom of plastered gable wall (Fig. 6).

After 2nd loading with east-directioned and $20 \mathrm{~mm}$ beginning translatory motion, no damages were occurred in addition to the 1 st loading. At the end of 3rd loading with west-directioned and $20 \mathrm{~mm}$ beginning translatory motion, the microcracks on the plastered gable wall increased, a displacement was occurred by ridge board of gable wall without plaster outwards the roof and slidings occurred in some tiles (Figs. 7 and 8).

In the 4th loading with east-directioned and $30 \mathrm{~mm}$ beginning translatory motion, the displacement which occurred at the ridge board of gable wall without plaster outwards the roof increased a bit more and its length reached up to "cm". The slidings occurred in tiles significantly increased. It was observed that vertical cracks occurred in the medium line bricks of gable wall without plaster (Fig. 9). In addition to this, micro plaster cracks occurred at the top of plastered gable wall (Fig. 10).

At the end of the 5th loading with west-directioned and $30 \mathrm{~mm}$ beginning translatory motion, there was a little increase in the damages determined with the 4th loading. In the 6th loading with east-directioned and $40 \mathrm{~mm}$ beginning translatory motion, the plaster cracks increased on the
Table 1. Measured accelerations for shaking table.

\begin{tabular}{cccc}
\hline $\begin{array}{c}\text { Loading } \\
\text { number }\end{array}$ & $\begin{array}{c}\text { Beginning } \\
\text { translatory } \\
\text { motions } \\
(\mathrm{mm})\end{array}$ & $\begin{array}{c}\text { Max. accelaration } \\
\text { in the shaking } \\
\text { table } \\
\left(\mathrm{cm} / \mathrm{s}^{2}\right)\end{array}$ & $\begin{array}{c}\text { Loading } \\
\text { direction }\end{array}$ \\
\hline 1 & 15 & - & West \\
2 & 20 & - & East \\
3 & 20 & - & West \\
4 & 30 & - & East \\
5 & 30 & 939.9869 & West \\
6 & 40 & 1552.9390 & East \\
7 & 30 & - & West \\
8 & 30 & - & West \\
9 & 45 & - & East \\
10 & 45 & 2355.7030 & East \\
\hline
\end{tabular}

plastered gable wall (Fig. 11). The slidings observed in tiles and ridge tiles ${ }^{5}$ significantly increased.

In the 7th loading with west-directioned and $30 \mathrm{~mm}$ beginning translatory motion, an expansion was observed in the cracks of the gable wall. The slidings in the tiles and ridge tiles also increased (Fig. 12).

\footnotetext{
${ }^{5}$ TBC-562: clay rooting tiles and ridge tiles
} 


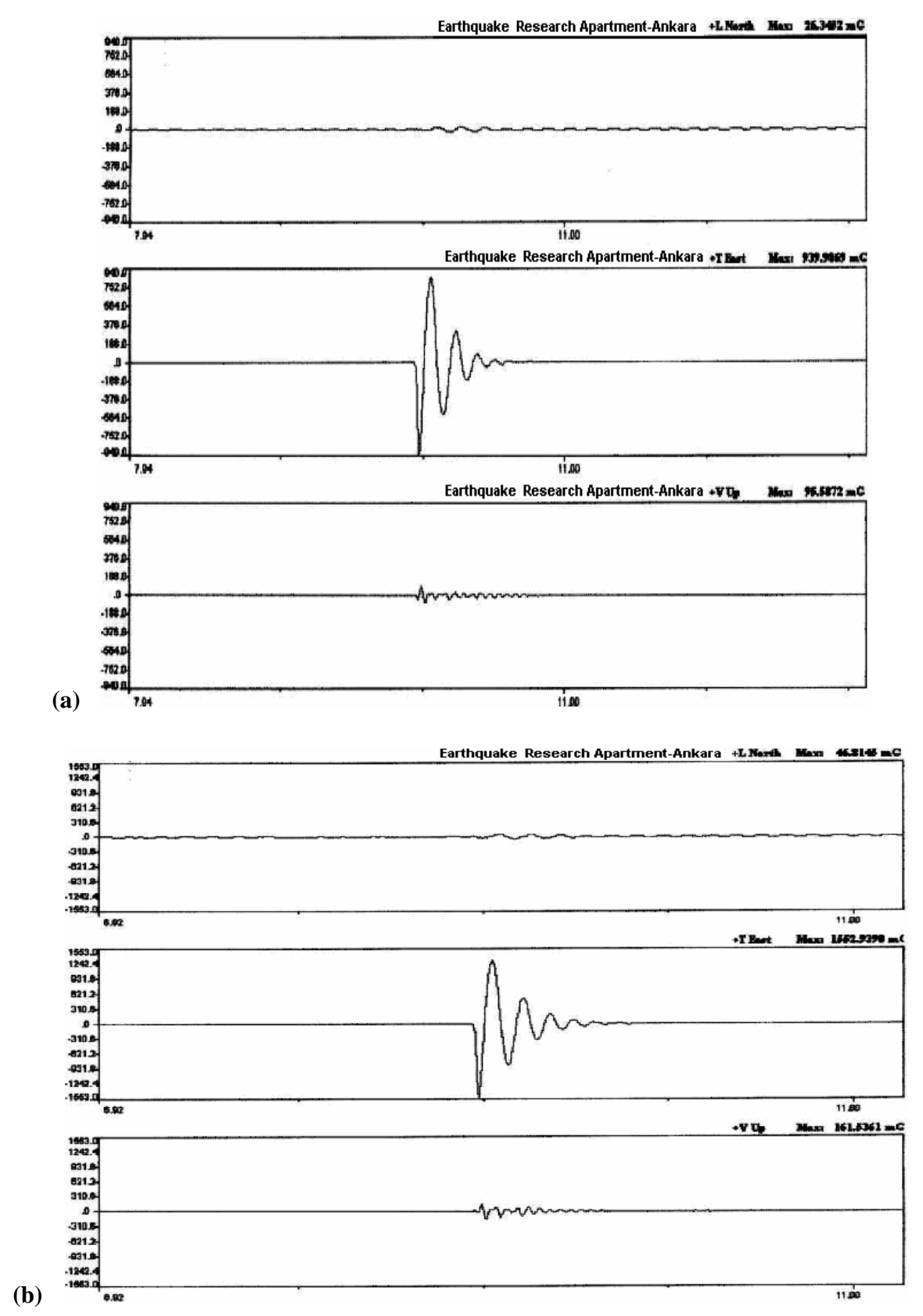

Fig. 5. Max. accelerations measured for the 1st experiment. (a) Maximum accelarations measured for the fifth loading. (b) Maximum accelarations measured for the sixth loading. (c) Maximum accelarations measured for the tenth loading.

The 8 th loading was applied with $30 \mathrm{~mm}$ beginning translatory motion in the west direction. After loading, the displacement occurred at the top of the gable wall without plaster increased and reached up to $8 \mathrm{~cm}$ (Fig. 13). The slidings observed in tiles and ridge tiles increased even more.

At the end of the 9th loading with $45 \mathrm{~mm}$ beginning translatory motion applied from the east, the length of the displacement observed at the top of the gable wall without plaster reached up to $13 \mathrm{~cm}$ (Fig. 14).
In the 7th loading with $45 \mathrm{~mm}$ beginning translatory motion applied from the east direction, the plaster cracks of plastered gable wall increased (Fig. 15). The slidings observed in tiles and ridge tiles significantly increased. The last line bricks of gable wall without plaster collapsed by sliding from the roof (Fig. 16).

After experiments, the gable walls were collapsed by sledge hammer.

a) The inside of the roof was investigated after the collapse of gable wall without plaster. 


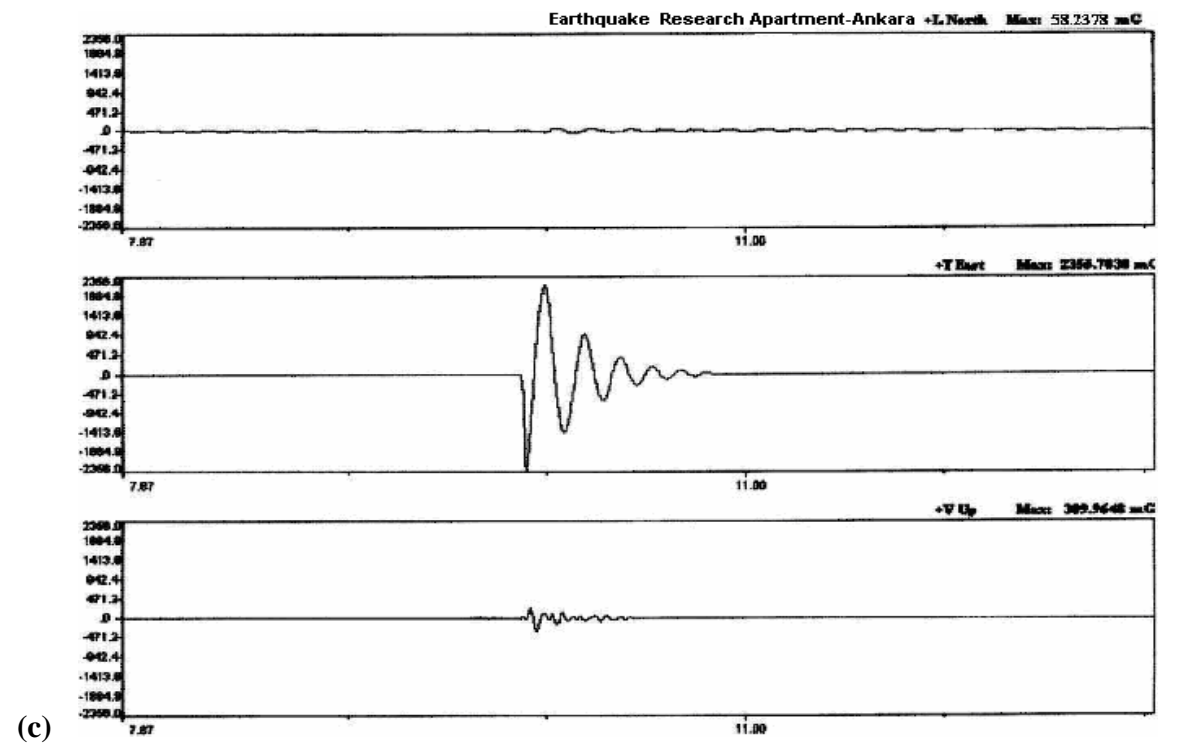

Fig. 5. Continued.

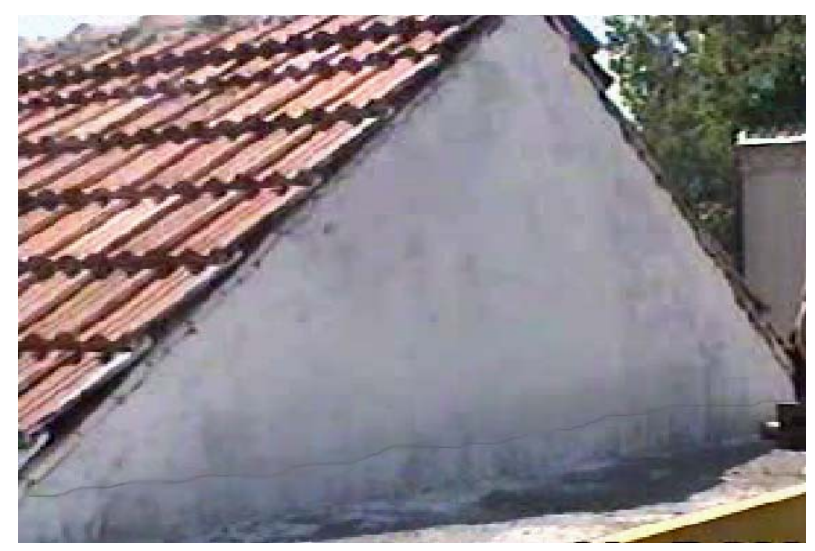

Fig. 6. Microcracks occurred on plastered gable wall.

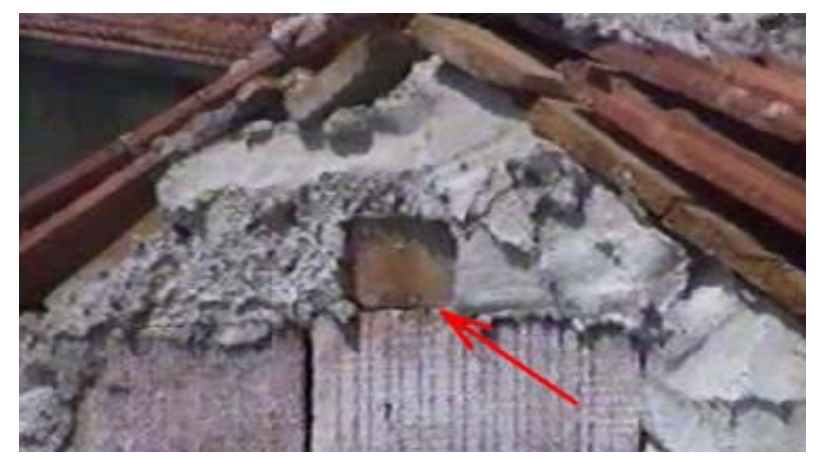

Fig. 7. The view of gable wall without plaster.
Table 2. Measured accelerations for shaking table.

\begin{tabular}{cccc}
\hline $\begin{array}{c}\text { Loading } \\
\text { number }\end{array}$ & $\begin{array}{c}\text { Beginning } \\
\text { translatory } \\
\text { motions } \\
(\mathrm{mm})\end{array}$ & $\begin{array}{c}\text { Max. accelaration } \\
\text { in shaking table }\end{array}$ & $\begin{array}{c}\text { Loading } \\
\text { direction }\end{array}$ \\
\hline 1 & 5 & - & Wal(mG) \\
2 & 15 & 1611.6930 & West \\
3 & 20 & 1054.2600 & East \\
4 & 20 & 1762.4400 & West \\
5 & 25 & 1295.7540 & East \\
6 & 30 & 2412.7090 & West \\
\hline
\end{tabular}

b) At the end of the investigation, the outside plaster cracks observed at the level of first line bricks of plastered gable wall were also observed in the inside plaster (Fig. 17).

c) Moreover, any noticeable changes in the displacement, fracture or crack were not observed in the investigated roof members (bay, purlin, rafter, etc.).

\subsection{Second experiment and its results}

The second experiment was performed on the gabled cradle roof system which does not get vertical load from the roof members. 6 beginning translatory motions were applied to the shaking table in the experiment and then it was decompressed. The total period for the oscillations occurred during experiments was approximately 7-10 s. Five measurable table accelaration values during shaking are given in Table 2 and as a graphic in Fig. 18. The weight of the roof was calculated as approximately 4.3 tons. Since an accelaration meter was not installed on the roof, the horizontal loads that affected the roof were not calculated also in this experiment. 


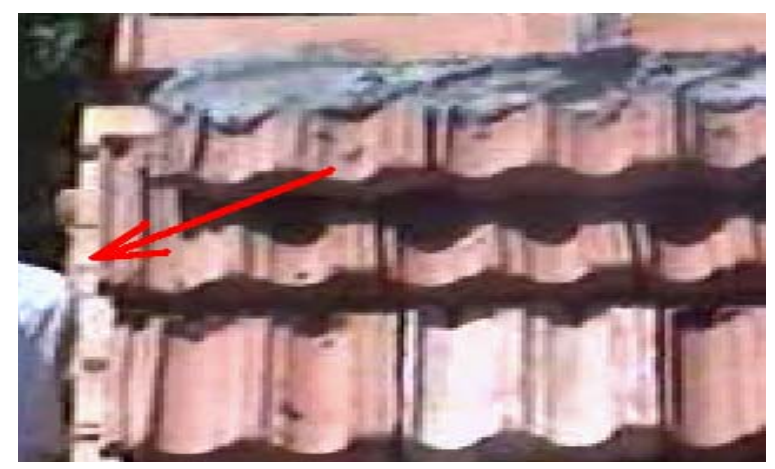

Fig. 8. Sliding occurred on tiles.

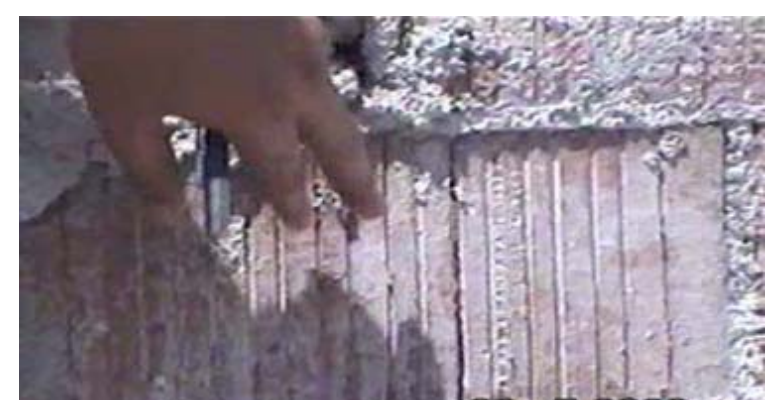

Fig. 9. Vertical cracks occurred on bricks.

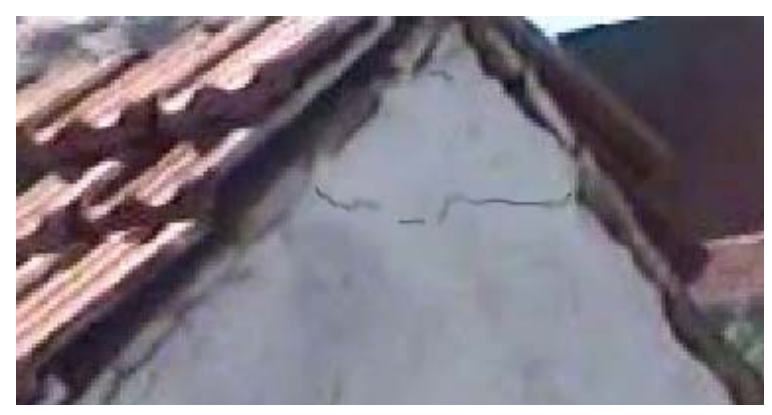

Fig. 10. The view of plastered gable wall.

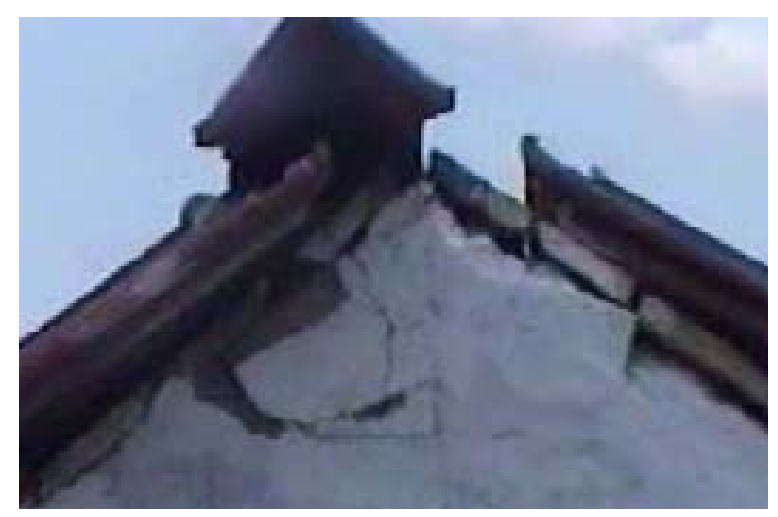

Fig. 11. The view of plastered gable wall cracks.
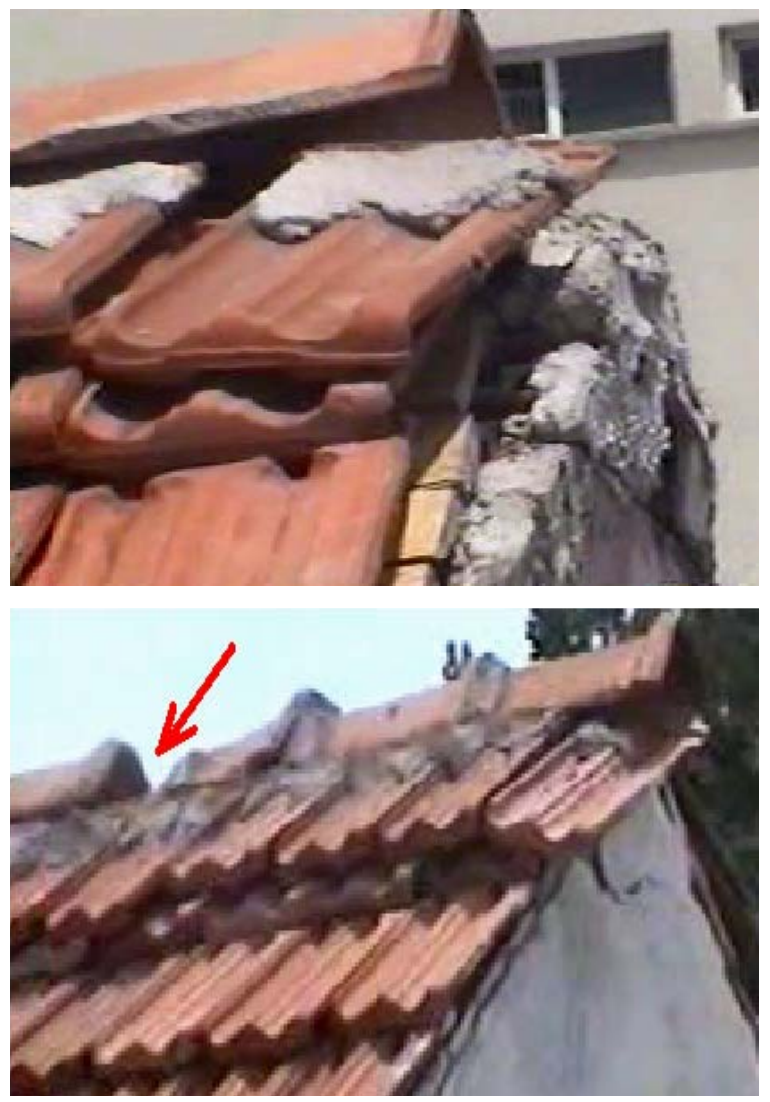

Fig. 12. Damages occurred with 7 th loading.

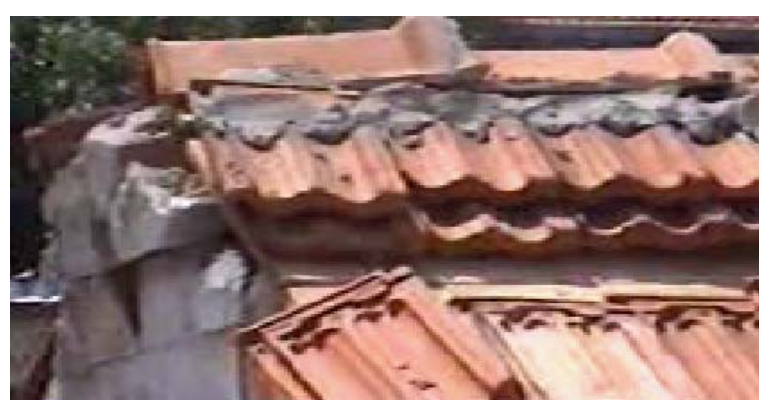

Fig. 13. The view of gable wall without plaster.

After 1st loading with $15 \mathrm{~mm}$ beginning translatory motion applied from the west, microcracks were formed on the coping of plastered gable wall (Fig. 19).

In the 2nd loading with west-directioned and $15 \mathrm{~mm}$ beginning translatory motion, microcracks formed on the coping after 1st loading increased a bit more. The plastered gable wall had a $2 \mathrm{~cm}$ outwards displacement at the top (Fig. 20). The plaster cracks that can be seen in Fig. 21 occurred at the level of lower bricks of plastered gable wall. 


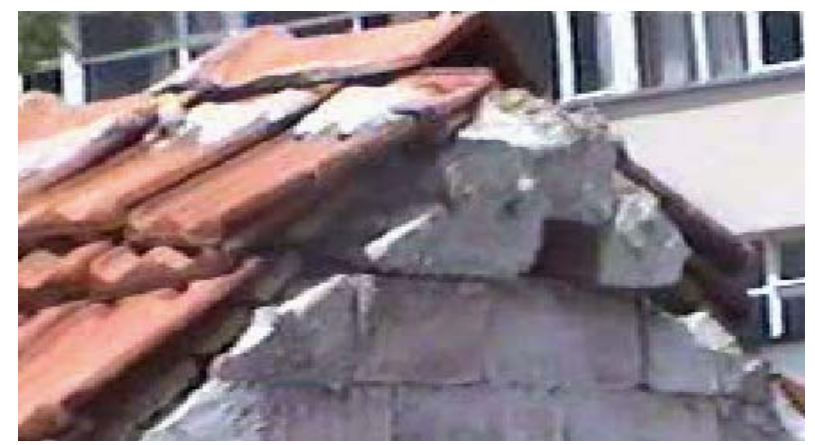

Fig. 14. The view of gable wall without plaster at the end of the 9 th loading.

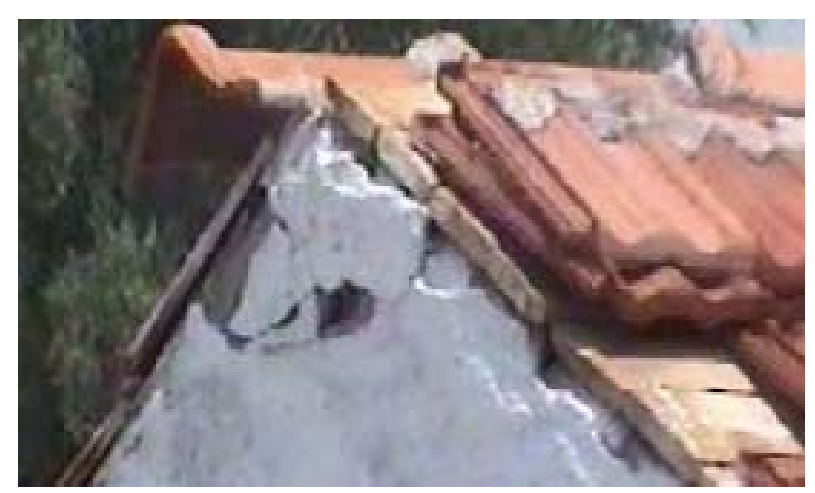

Fig. 15. The view of top of plastered gable wall at the end of the 10th loading.

At the end of 3rd loading with east-directioned and $20 \mathrm{~mm}$ beginning translatory motion, the microcracks formed on the plastered gable wall at the end of 2 nd loading increased, $2 \mathrm{~cm}$ outwards displacement at the top of gable wall without plaster (Fig. 22) and slidings in the tiles occurred.

In the 4th loading with $20 \mathrm{~mm}$ beginning translatory motion in the west direction, the displacement occurred at the top of the plastered gable wall increased and reached up to $8 \mathrm{~cm}$ (Fig. 23). The slidings observed in the tiles significantly increased.

At the end of 5th loading with $25 \mathrm{~mm}$ beginning translatory motion in the east direction, the displacement occurred at the top of the gable wall without plaster increased and reached up to $5 \mathrm{~cm}$.

At the end of 6 th loading with $30 \mathrm{~mm}$ beginning translatory motion in the west direction, the plastered gable wall collapsed outwards as a whole at the level of plaster cracks occurred previously (Fig. 24). The slidings observed in the tiles and ridge tiles significantly increased. The displacement occurred at the top of the gable wall without plaster increased and reached up to approximately $6 \mathrm{~cm}$.

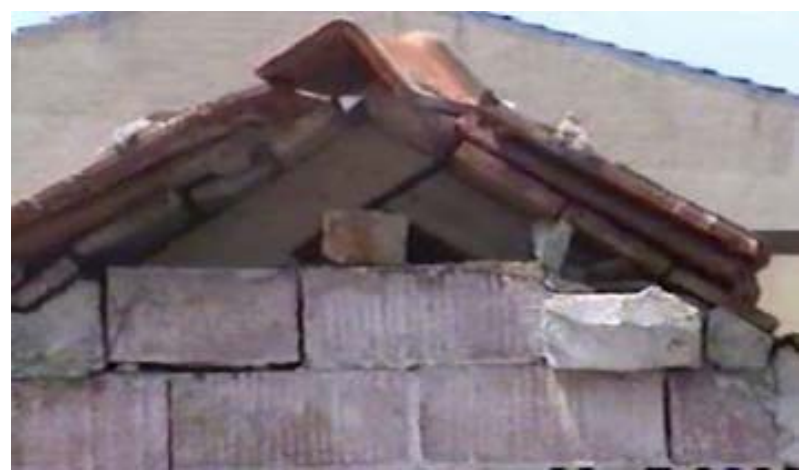

Fig. 16. Damages occurred with 10th loading.

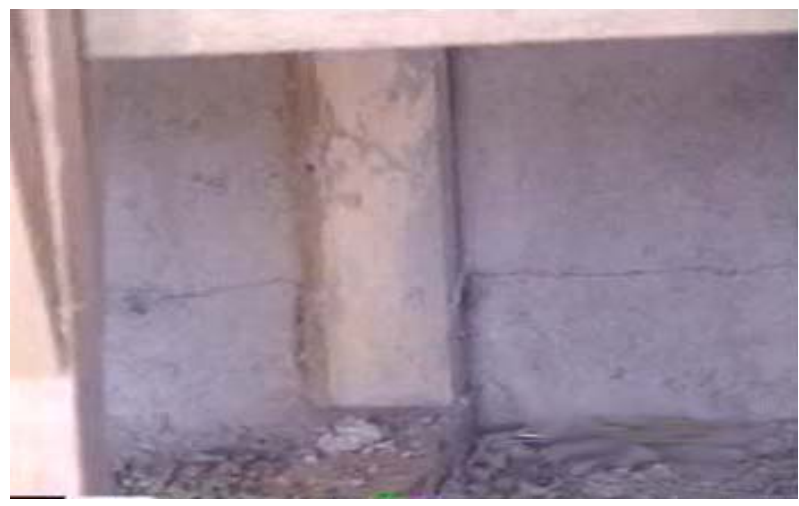

Fig. 17. Cracks occurred in inside plaster.

In this experiment, it was considered that the following cases were effective among the reasons for the collapse of plastered gable wall before the one without plaster;

1. the production of plaster mortar and pointing stuff used in bonding of gable wall with the cement stored in humid medium,

2. $2 \mathrm{~cm}$ gap left between plastered gable wall and the roof while bonding,

3. using imprecise labour while bonding the plastered gable wall.

In the investigation of roof members (bay, purlin, rafter, etc.) after the experiment, any noticeable changes in the displacement, fracture or crack were not observed.

\section{Results and suggestions}

As a result of the experiments, significant information was obtained about the behaviours of roof gable walls under the effect of horizontal dynamic loads. The results of experiments and researches are summarized as follows. 
M. Kamanli and F. S. Balik: The behaviour of roof gable walls under the effect of earthquake load
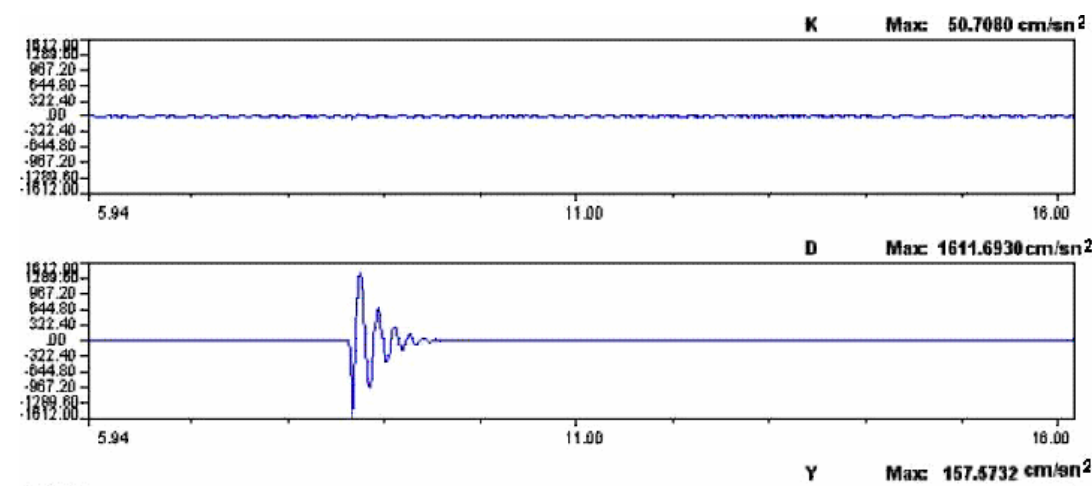

(a)
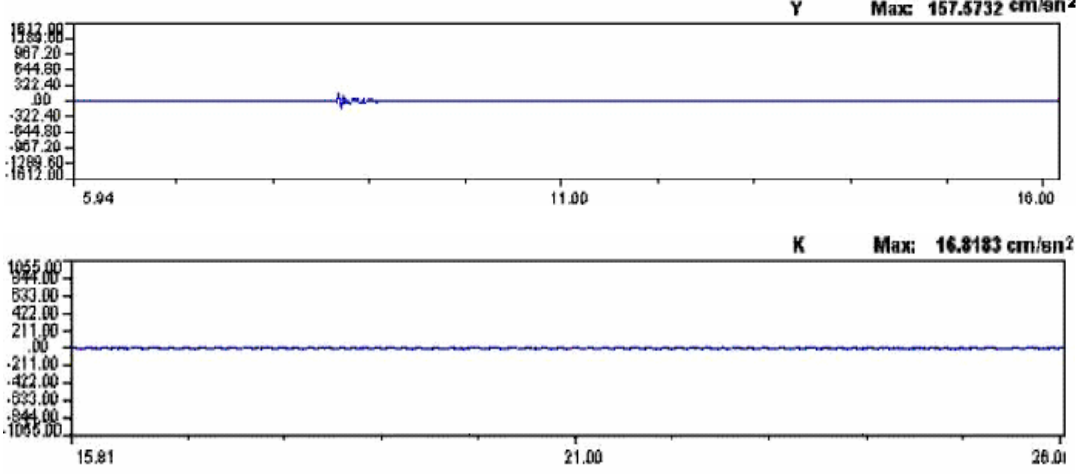

D Maxe $1054.2600 \mathrm{~cm} / \mathrm{an} 2$

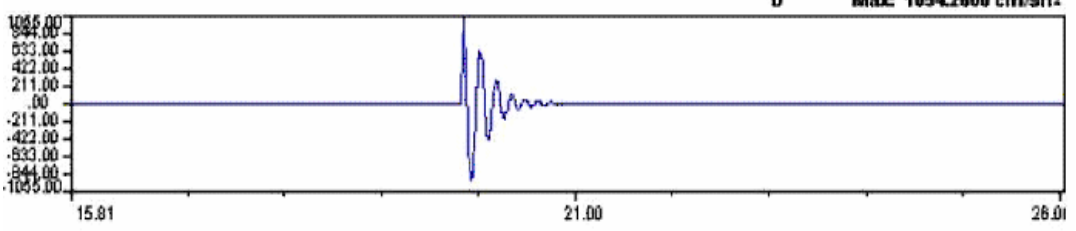

Y Max: 64.9341 $\mathrm{cm} / \mathrm{an}$

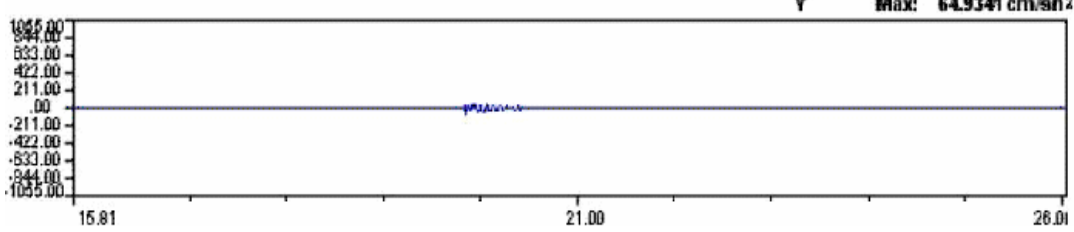

(b)
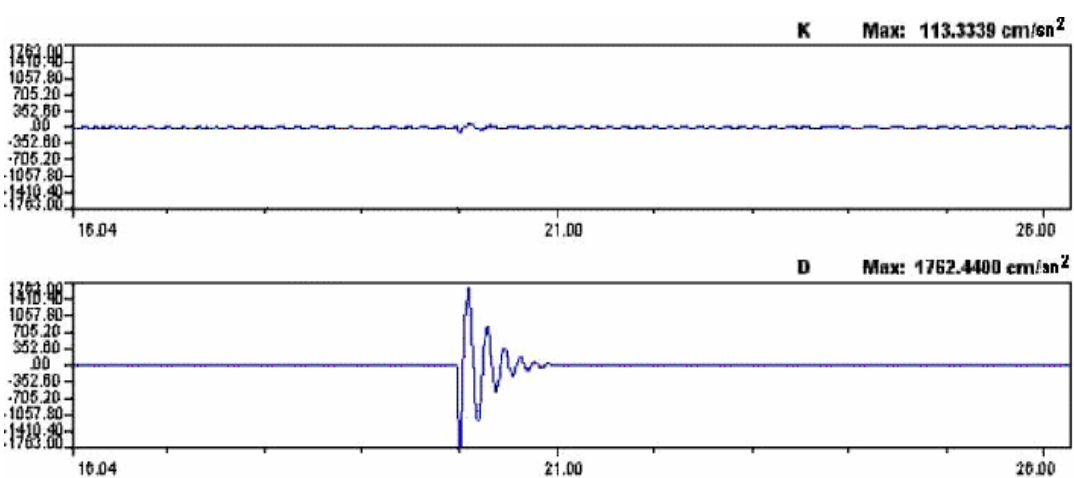

Y Max: $221.4061 \mathrm{~cm} / \mathrm{sn}^{2}$

(c)

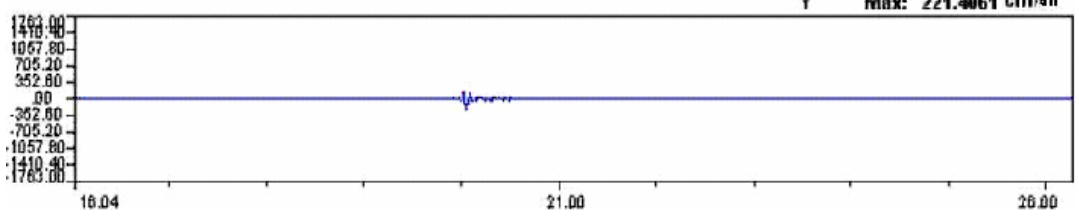

Fig. 18. Max. accelerations measured for the 2nd experiment. (a) Maximum accelarations measured for the 2nd loading. (b) Maximum accelarations measured for the 3rd loading. (c) Maximum accelarations measured for the 4th loading. (d) Maximum accelarations measured for the 5th loading. (e) Maximum accelarations measured for the 6th loading. 

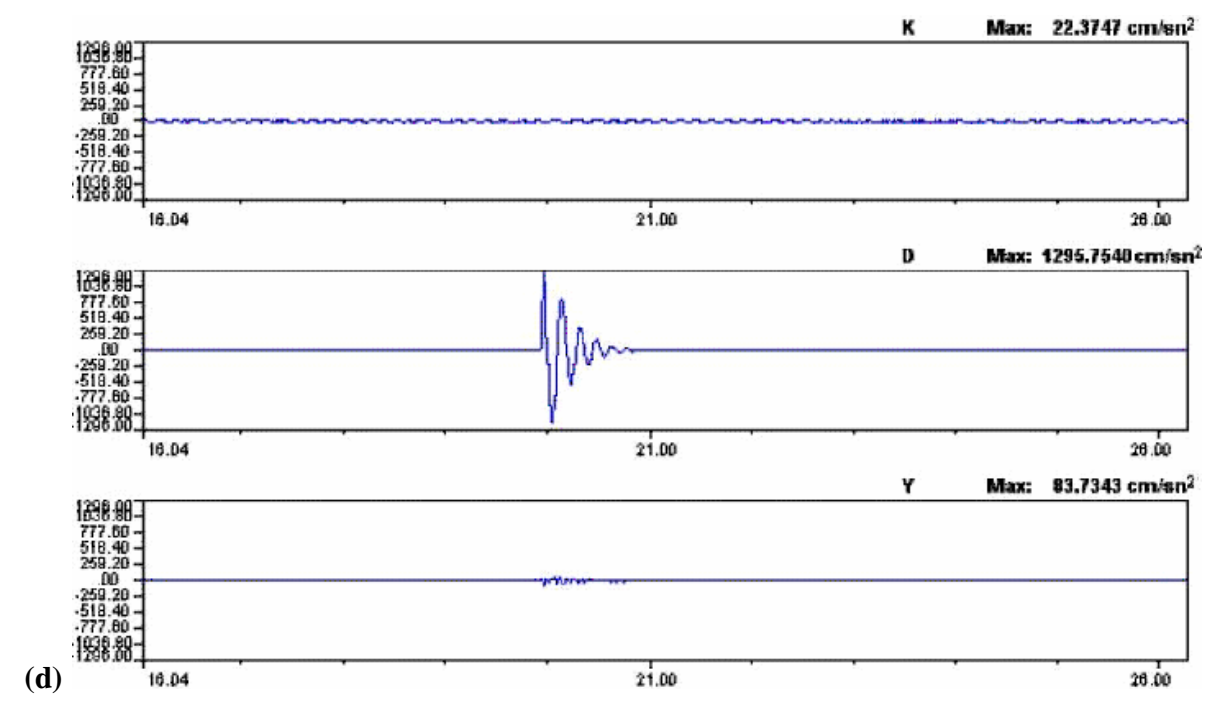

(d)
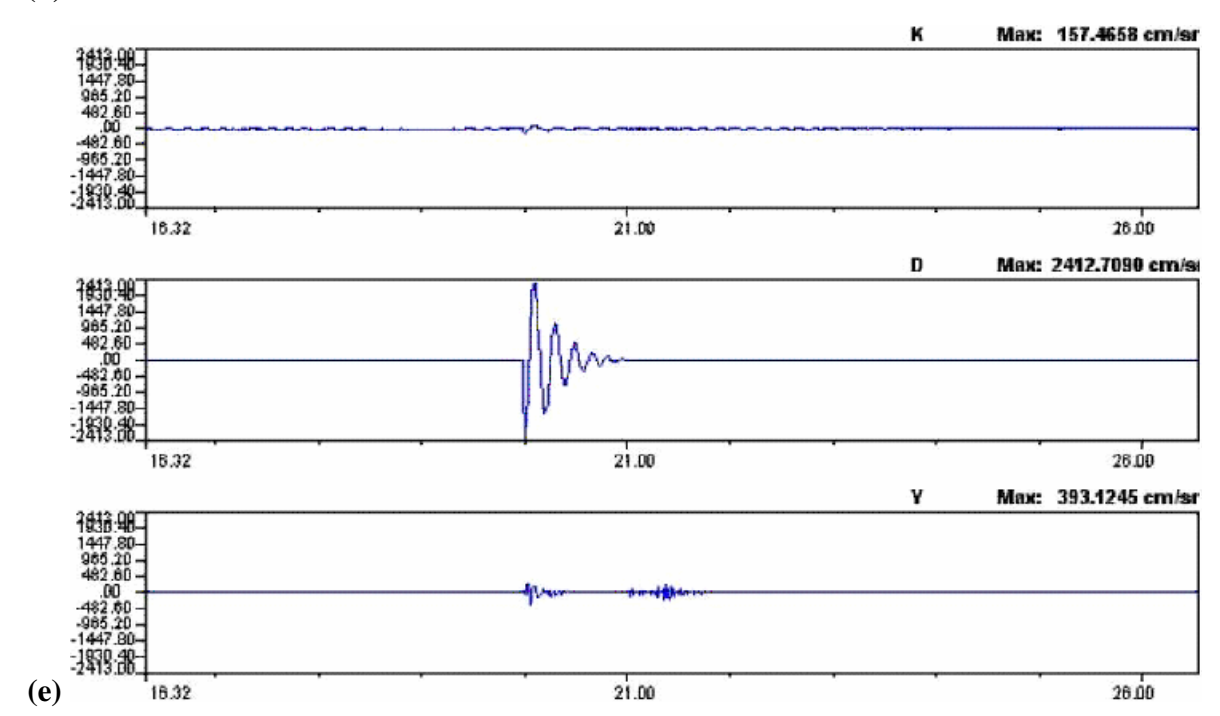

Fig. 18. Continued.

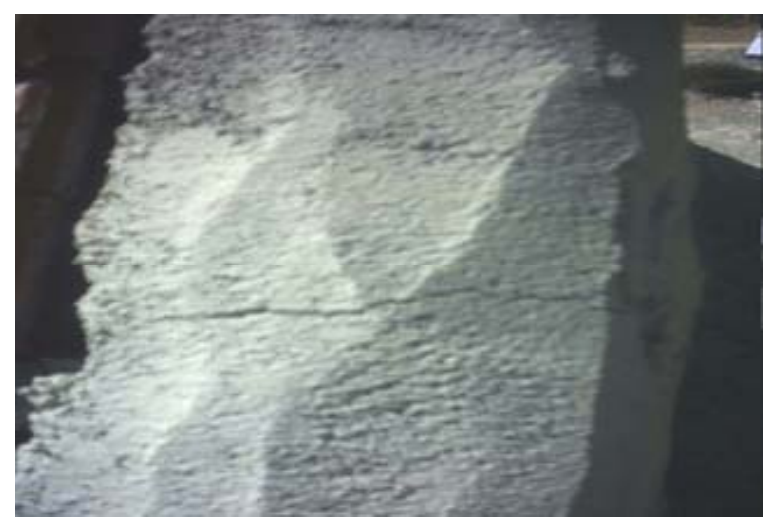

Fig. 19. Damages occurred with 1st loading.

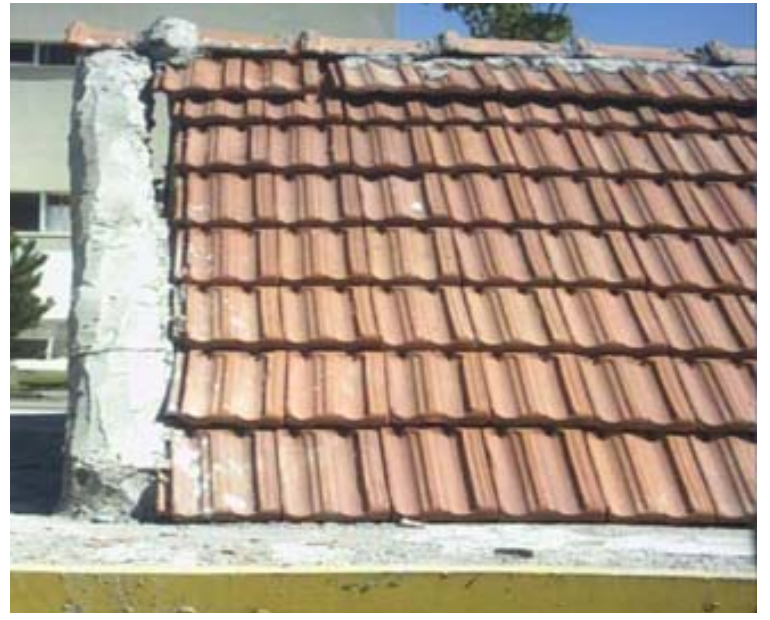

Fig. 20. The view of plastered gable wall. 


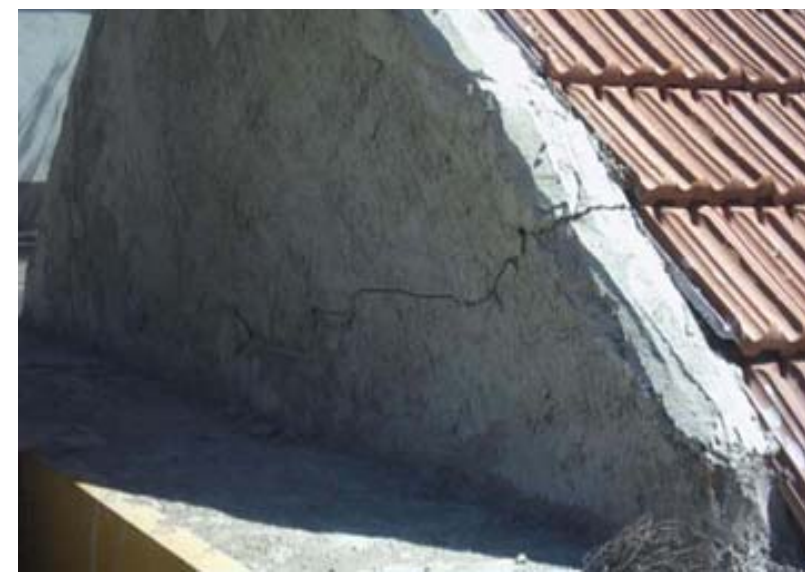

Fig. 21. Plaster cracks occurred with 2 nd loading.

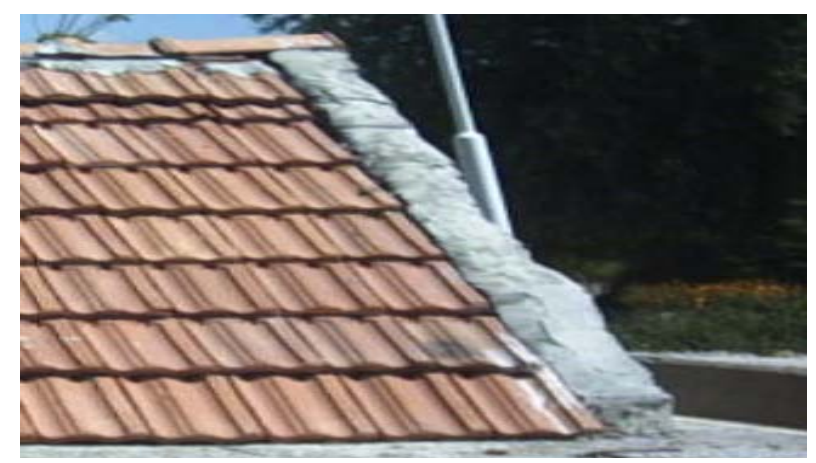

Fig. 22. The view of gable wall without plaster at the end of $3 \mathrm{rd}$ loading.

At the end of the first experiment on gabled cradle roof system getting load from roof members, it was observed that plastered gable walls were more strengthful than the ones without plaster. At the end of the second experiment on gabled cradle roof system which does not get vertical load from roof members, on the other hand, it was observed that the strengths of gable walls significantly reduced due to unqualified materials and labour usage in bonding of gable walls. In other words, the plastered gable walls collapsed by out-of-plane tumbling down before gable walls without plaster due to the reasons mentioned above instead of being more strengthful than the gable walls without plaster against horizontal dynamic loads. At the end of the first and the second experiment, it was observed that the gable walls getting load from roof members are more strengthful against horizontal dynamic loads than the ones which do not get loads. For this reason, constructing the gable walls in conjunction with roof scaffold contributes to an increase in the strength of them under the effect of horizontal loads.

In the investigation of roof scaffold members after both of the experiments, any noticeable changes in the displacement, fracture or crack were not observed.

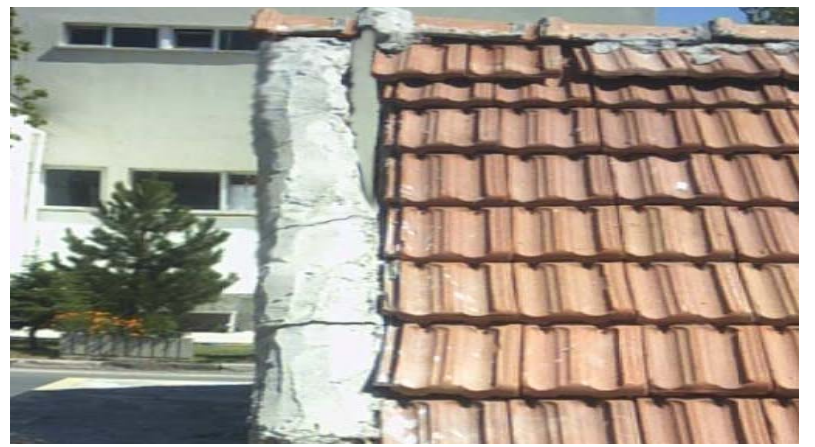

Fig. 23. The view of plastered gable wall at the end of 4 th loading.

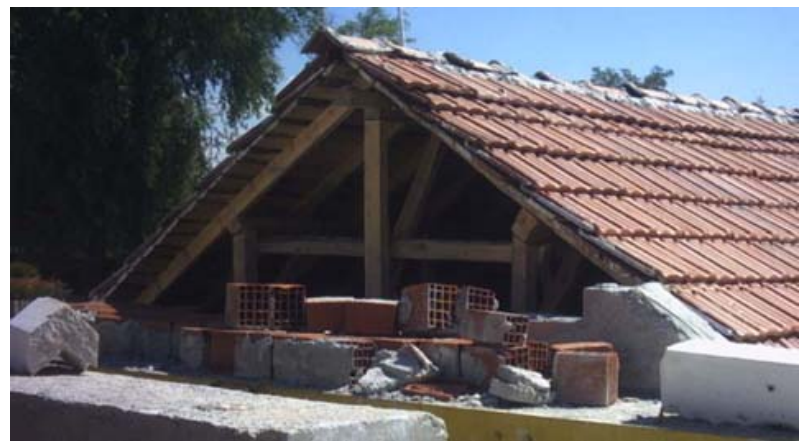

Fig. 24. The view of collapsed plastered gable wall at the end of 6th loading.

When the results of the experiments were generally taken into consideration, it was realized that the gable walls in both roof systems would partly or completely collapse even under the effect of a little horizontal dynamic load. Since our country is mostly an earthquake-prone country, the roof gable walls which are constructed as masonry constructions threatens the security of life and property. Therefore, it's necessary to construct roof gable walls more strengthful against the effect of earthquake load in our country. Consequently, the following precautions should be taken to construct roof gable walls more strengthful and more reliable against the effect of earthquake load.

1. As it's known, if the gable wall of a masonry construction in disaster area is set on a horizontal beam at the uppermost floor and its height exceeds $2 \mathrm{~m}$, the vertical and skewed beam should be constructed. Application of this not only for roof gable walls but also for masonry constructions is accepted as the first precaution to increase the stregth and construcion security of the gable walls.

2. As a second precaution, the gable walls should be constructed from reinforced concrete materials which meet both their tensile strength and compressive force requirements. 
Acknowledgements. This study was prepared from M.Sc. thesis of F. Suleyman Balik with the supervision of Mehmet Kamanli which was accepted by SU Institute of Natural and Applied Sciences.

Edited by: M. E. Contadakis

Reviewed by: two anonymous referees

\section{References}

Balik, F. S. and Kamanli, M.: Concrete Technology, Atlas Publication Distribution, Istanbul, 2003.

Balik, F. S.: The Behaviours of Roof Gable Walls under the Effect of Earthquake Load, M.Sc. Thesis, SU Institute of Natural and Applied Sciences, Konya, 2004.

Bayülke, N.: A Simple Shaking Table used for the Determination of Earthquake Behaviours of Rural Dwellings, Bulletin of Ministry of Public Works and Settlement, 92, 202-210, Ankara, 1986.

Bayülke, N., Dogan, A., and Hurata, A.: A Report for Shaking Table Experiment of a Model Construction with Çimger Construction System produced by Ankara Reconstruction Limited Company, Ministry of Public Works and Settlement General Directorate of Technical Research and Application Department of Earthquake Research, Ankara, 1986.

Bayülke, N., Doğan, A., and Hürata, A.: The Report for Shaking Table Experiment of Masonry Constructions Constructed of Vertically Perforated Bricks, Ministry of Public Works and Settlement General Directorate of disaster Affairs, Department of Earthquake Research, Ankara, 1989.

Bayülke, N.: The Report for Shaking Table Experiment of Rebuilt Brick Masonry Construction, Ministry of Public Works and Settlement General Directorate of disaster, Affairs Department of Earthquake Research, Ankara, 1990.
Paulson, T. J., Abrams, D. P., and Mayes, R. L.: Shaking Table Study of Base Isolation for Mansory Buildings, J. Struct. Eng.ASCE, 117(11), 3315-3336, USA, 1991.

Turkish Earthquake Code (TEC): Regulations on Structures Constructed in Disaster Regions, Ministry of Public Works and Settlement, 2007.

Klemenc, I. and Tomazevic, M.: Verification of seismic Resistance of Confined Masonry Buildings, Earthq. Eng. Struct. D., 26, 1073-1088, 1997.

Hahn, G. D.: Correlation of Seismic Responses of Structures, J. Struct. Eng.-ASCE, 123(4), 405-413, 1997.

Mengi, Y., Mc Niven, H., and Tanrikulu, A.: Model For Nonlinear Earthqauake Analysis of Unreinforced Brick Masonry Buildings, Comput. Struct., 41(4), 801-812, 1991.

Kaltakci, M. Y., Arslan, M. H., and Korkmaz, H. H., Öztürk, M.: An Investigation on Failed or Damaged Reinforced Concrete Structures under their Own Weight in Turkey, Eng. Fail. Anal., 14(6), 962-969. 2007.

Schweier, C., Markus, M., and Steinle, E.: Simulation of earthquake caused building damages for the development of fast reconnaissance techniques, Nat. Hazards Earth Syst. Sci., 4, 285293, 2004, http://www.nat-hazards-earth-syst-sci.net/4/285/2004/.

Cervone, G., Singh, R. P., Kafatos, M., and Yu, C.: Wavelet maxima curves of surface latent heat flux anomalies associated with Indian earthquakes, Nat. Hazards Earth Syst. Sci., 5, 87-99, 2005, http://www.nat-hazards-earth-syst-sci.net/5/87/2005/. 